\title{
The pectoral-sternalis complex: an unusual case report
}

\author{
BALA, M. ${ }^{1}{ }^{*}$, PASSI, D. K. ${ }^{2}$ and KAUSHAL, S. ${ }^{3}$ \\ ${ }^{1}$ Medical college Mullana, Ambala. Haryana. India (Anatomy), Ambala - Índia \\ ${ }^{2}$ Civil Hospital, Samana, Patiala (Civil Hospital, Samana, Patiala), 147101 Patiala - Índia \\ ${ }^{3}$ Govt. Medical College, Patiala (Govt. Medical College, Patiala), 147001 Patiala - Índia \\ *e-mail: drmanju14@yahoo.in
}

\begin{abstract}
A unilateral absence of sternocostal fibers of pectoralis major muscle with unilateral presence of sternalis muscle has been noticed in right side of an adult male cadaver during routine dissection. All slips of pectoralis major muscle as well sternalis muscle innervated by medial and lateral pectoral nerves. Absence of pectoralis major has been described extensively, both as an isolated anomaly, with varying levels of hypoplasia, and in association with congenital syndromes. But the partial hypoplasia of pectoralis muscle with compensatory presence of one of the rare muscle of anterior thoracic wall the sternalis muscle make this case as unique and rare. This finding adds to our existing knowledge for the origin of sternalis, an identity not explored fully yet. Awareness of anomalous pectoralis major musculature as well presence of sternalis muscle is important for reconstructive surgeons who perform mastectomy and for radiologists during interpretation of skiagrams.
\end{abstract}

Keywords: pectoralis major muscle, sternalis muscle, innervation.

\section{Introduction}

The pectoralis major muscle is a thick triangular fan shaped muscle of anterior chest wall. The clavicular head arises from the medial half of the anterior surface of the clavicle while the sternocostal head arises from the lateral part of the anterior surface of the manubrium and body of sternum and from the aponeurosis of the external oblique muscle over the upper attachment of rectus abdominis. The muscle inserts laterally in the intertubercular groove of the humerus. The pectoralis major muscle is a prime flexor, chief adductor and medial rotator of the humerus. Innervation is by the medial and lateral pectoral nerves (McMINN, 1998). Familiarity with the anatomic variations of pectoral musculature is important as identifying them early to achieve appropriate dissection planes during surgery of the chest wall (DHURIA, MEHTA, LOH et al., 2009).

Like most limb girdle muscles, there is some doubt about how much of pectoralis muscle developed from the limb bud and how much from myotomes of the trunk, with migration in either direction. On dissection 1 body in 20 shows, the presence of vertical musculoaponeurotic fibres on the surface of the pectoralis major alongside the sternum called rectus sternalis muscle (McMINN, 1998). Some authors find it to be a variation of pectoralis major muscle when innervated by pectoral nerves, while others find that because it is often innervated by intercostal nerves, it is an aberrant abdominal muscle (ATRICAN, COSKUN, SARIKCIOGLU et al., 2006).

The sternalis muscle is often bilateral and sometimes associated with the variation of the pectoralis major muscle (ATRICAN, COSKUN, SARIKCIOGLU et al., 2006). In the clinical practice, it is essential for the radiologists and the surgeons to acknowledge this anomaly as it may pose a diagnostic dilemma, by mimicking a malignant breast mass on mammography, CT scan or MR imaging and thus an unnecessary exploratory surgery can be avoided (KUMAR,
RATH, SHARMA et al., 2003). We report here an example of appearance of the sternalis muscle with accompanying pectoralis major muscle anomaly.

\section{Case Report}

During routine dissection, unusual unilateral variation of pectoral musculature was seen on right side of an adult male cadaver. The clavicular slips of pectoralis major muscle were seen arising as usual from medial half of the anterior surface of the clavicle with absence of sternocostal slips whereas the muscular slips from aponeurosis of external oblique muscle were present forming the anterior fold of axilla and getting insertion on lateral lip of inter tubercular sulcus. Interestingly there was presence of one of the important and rare muscle of anterior thoracic wall, the sternalis muscle arising unilaterally from aponeurosis of external oblique muscle along with aponeurotic fibers of pectoralis major muscle, running vertically, parallel and lateral to sternum and then merging with then merging with manubrium sterni (Figure 1). All muscular slips of pectoralis major muscle as well sternalis muscle were getting innervation from medial and lateral pectoral nerves as in (Figure 2). The unique feature of present case study was the appearance of anterior thoracic wall having triangular pectoralis major muscle inspite of fan shaped. Clavicular slips, slips from external oblique muscle, formed the arms of the triangle and sternalis muscle with deficient sternocostal slips in center. The pectoralis major was normal on left side.

\section{Discussion}

Anomalous pectoral musculature has been usually reported earliar in literature. Bilateral partial absence of clavicular head of pectoralis major with $2.5 \mathrm{~cm}$ gap was found between the clavicular and sternocostal head 


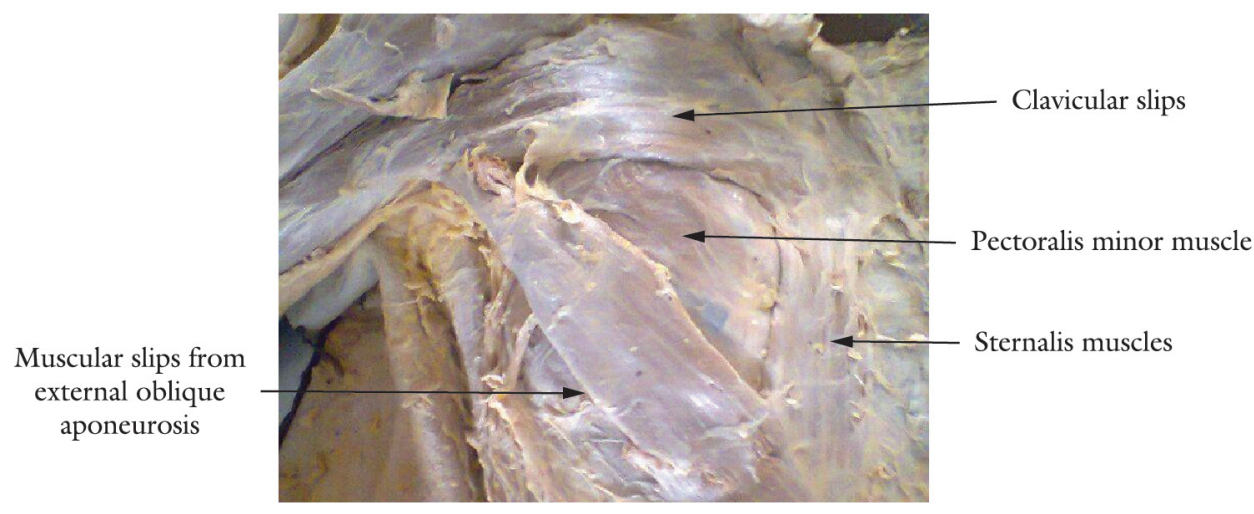

Figure 1. Sternalis muscle with deficient sternocostal slips of pectoralis major muscle.

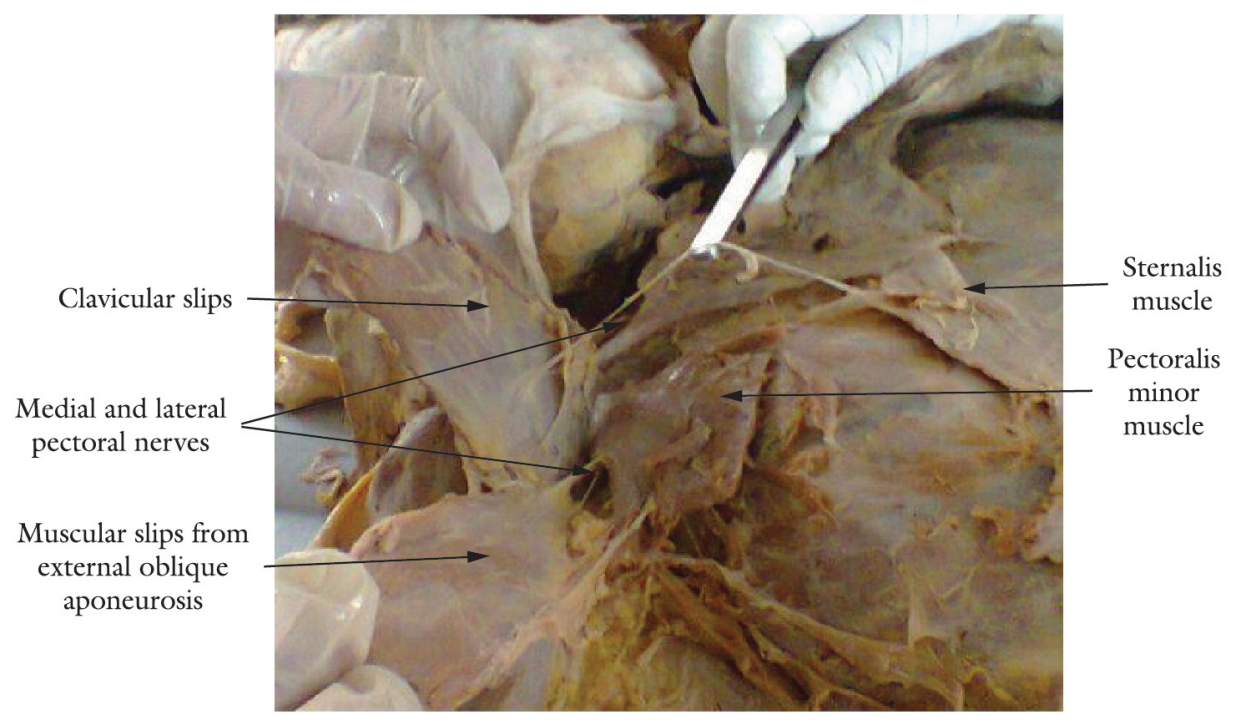

Figure 2. Innervation of pectoralis major and sternalis muscle by medial and lateral pectoral nerves.

(GOVAL, HARJEET and GUPTA, 2006). The sternocostal head is most commonly poorly developed and when absent it is accompanied by hypertrophy of clavicular head. Thus the primitive muscle mass, giving rise to pectoral muscles, attaches to the clavicle first, then fans out and subsequently attaches to the sternum and ribs. When the developmental arrest is partial, the sternocostal fibers are more likely to be affected, sparing clavicular fibers (MOSCONI and KAMATH, 2003). In the present case, partial absence of pectoralis muscle accompanied by presence of unilateral sternalis muscle has been reported.

The sternalis muscle is a fleshy band of longitudinal fibers of varying length and width, located close to and generally parallel to the sternum. When typical, it arises from the sheath of the rectus abdominis muscle, aponeurosis of the external oblique muscle, pectoralis major muscle, or costal cartilages and ends above onto the upper costal cartilages, manubrium, or may be joined to the sternal head of the sternocleidomastoid muscle (SALMONS, 1995). When the sternalis accompanies partial or complete congenital absence of the pectoralis major muscle, it may achieve significant size (KITAMURA, YOSHIOKA, KANEDA et al., 1985). In the present case, sternalis muscle was seen arising from aponeurosis of the external oblique muscle and continued above up to manubrium and had significant size.

Majority of sternalis muscles are supplied by intercostals Nerves (MISRA, 1954; SHEN, CHIEN and LEE, 1992; JENG and SU, 1998). Additionally, participation of the pectoral nerves has also been reported (KIDA, IZUMI and TANAKA, 2003). In the present case report, pectoral nerves were the sole supply to sternalis muscle.

O'Neill and Folan-Curran (1998) reported the direct connection of muscle fibers between the sternalis and pectoralis major muscles. Additionally, Kida, Izumi and Tanaka (2003) reported the partial absence of the sternocostal portion of the pectoralis major muscle. They suggested that the close relation of both muscles might show their origin, although a connection of muscle fibers did not always indicate a muscle origin. They supported the opinion of the sternalis muscle derivation from the pectoralis major muscle. Shinohara reported three laws (migration, fusion and separation) on nerve-muscle specificity. In the law of migration, the nerve is regarded as an indicator of the route along which the muscle mass originated and migrated (i.e. diaphragm). In the law of fusion, when a muscle is supplied by two different nerves, this muscle is considered 
to have been formed by fusion of two muscle mass, each of which was originally supplied by a separate nerve. Some muscle, e.g. the external oblique, are supplied both from the superficial and deep surfaces, and this dual surface supply is interpreted as suggesting that the muscle is a composite muscle. According to the law of separation, two different muscles supplied by a single nerve are considered to be derived from a single muscle mass (i.e. common muscle mass for the sternecleidomastoid and trapezius muscles) (SHINOHARA, 1996). We think that further studies should be performed to clarify the derivation of the sternalis muscle on the view of these laws. The present case report supports that both the muscles i.e. pectoralis major and sternalis developed from single muscle mass and further suggests that sternalis belongs to upper limb muscle.

It has been reported that in hypoplasia or deficit sternocostal head of pectoralis major, the clavicular head get hypertrophied (MOSCONI and KAMATH, 2003). In the present case, hypertrophy of clavicular head was not seen but by looking at the size of sternalis, the authors are of the opinion that during contraction of the muscle mass the contraction of sternalis brings the two heads of pectoralis major nearer to each other to compensate the action of the deficit part of pectoralis major.

During routine mammography, sternalis muscle may be visible as an irregular structure medially on the craniocaudal projection. It may be seen in the medial aspect of the breast on the craniocaudal view as a density with an ill-defined margin and can give rise to diagnostic confusion with a breast cancer (BRADLEY, HOOVER JUNIOR, HULKA et al.,1996). Systemic anomalies like anencephaly have been connected with presence of sternalis muscle (SCHULMAN and CHUN, 2005).

\section{Conclusion}

Prior knowledge of anatomic variations in pectoral musculature whether its absence, an additional slips or presence of sternalis muscle can prepare a surgeon to properly incorporate and utilize the variant anatomy for cosmetic augmentations during reconstructive breast surgery.

\section{References}

ATRICAN, RY., COSKUN, N., SARIKCIOGLU, L., SINDDEL, $M$. and OGUZ, N. Co-existence of the pectoralis quartus \& pectoralis intermedius muscles. Morphologie, 2006, vol. 90, n. 290, p. 157-159. http://dx.doi.org/10.1016/S1286-0115(06)74497-6

BRADLEY, FM., HOOVER JUNIOR, HC., HULKA, CA., WHITMAN, GJ., MCCARTHY, KA., HALL, DA., MOORE, R. and KOPANS, DB. The sternalis muscle: an unusual normal finding seen on mammography. American Journal of Roentgenology, 1996, vol. 166, n. 1, p. 33-36. PMid:8571900. http://dx.doi. org/10.2214/ajr.166.1.8571900

DHURIA, R., MEHTA,V., LOH, H., ARORA, J., ROY, S., SURI, R. and RATH, G. Unilateral quadripartite composition of pectoral major muscle: anatomical description and clinical implication.
Internatonal Journal of Morphology, 2009, vol. 27, n. 4, p. 12131216.

GOVAL, N, HARJEET and GUPTA, M. Bilateral variant origin of pectoralis major. Nepal Medical College, 2006, vol. 8, n. 1, p. 65-68.

JENG, H. and SU, SJ. The sternalis muscle: an uncommon anatomical variant among Taiwanese. Journal of Anatomy, 1998, vol. 193, n. 2, p. 287-288. PMid:9827644 PMCid:PMC1467848. http://dx.doi.org/10.1046/j.1469-7580.1998.19320287.x

KITAMURA, S., YOSHIOKA, T., KANEDA, M., MATSUOKA, K., CHEN, KL. and SAKAI, A. A case of the congenital partial defect of the pectoralis major-accompanied by the sternalis with enormous size. Kaibogaku Zasshi Journal of Anatomy, 1985, vol. 60, n. 6, p. 728-732. PMid:3834728

KUMAR, H., RATH, G., SHARMA, M., KOHLI, M. and RANI, B. Bilateral sternalis with unusual left sided presentation: a clinical Perspective. Yonsei Medical Journal, 2003, vol. 44, n. 4, p. 719-722. PMid:12950131. http://dx.doi.org/10.3349/ymj.2003.44.4.719

KIDA, MY., IZUMI, A. and TANAKA, S. Sternalis muscle: topic for debate. Clinical Anatomy, 2000, vol. 13, n. 2, p. 138-140. http:// dx.doi.org/10.1002/(SICI)1098-2353(2000)13:2<138::AIDCA8>3.0.CO;2-4

MCMINN, RMH. Upper limb. In: MCMINN, RMH. Last's Anatomy: regional and applied. $9^{\text {th }}$ ed. London: Churchill Livingstone, 1998. p. 54-55.

MOSCONI, T. and KAMATH, S. Bilateral asymmetric deficiency of the pectoralis major muscle. Clinical Anatomy, 2003, vol. 16, n. 4, p. 346-349. PMid:12794921. http://dx.doi.org/10.1002/ ca.10077

MISRA, BD. The sternalis muscle. Journal of the Anatomical Society of India, 1954, vol. 3, p. 47-48.

O'NEILL, MN. and FOLAN-CURRAN, J. Case report: bilateral sternalis muscles with a bilateral pectoralis major anomaly. Journal of Anatomy, 1998, vol. 193, n. 2, p. 289-292. PMid:9827645 PMCid:PMC1467849. http://dx.doi.org/10.1046/j.1469-

7580.1998.19320289.x

SALMONS, S. Gray's Anatomy. In WILLIAMS, PL., BANNISTER, LH., BERRY, M.,COLLINS, P.,DYSON,M.,DUSSEK,J.E.,FE RGUSON, M.W.J. (Eds.). Gray's anatomy. New York: ChurchillLivingstone, 1995. p. 838.

SCHULMAN, MR. and CHUN, JK. The conjoined sternalispectoralis muscle flap in immediate tissue expander reconstruction after mastectomy. Annals of Plastic Surgery, 2005, vol. 55, n. 6, p. 672-675. PMid:16327473. http://dx.doi.org/10.1097/01. sap.0000183940.39898.32

SHEN, CL., CHIEN, CH. and LEE, SH. A Taiwanese with a pair of sternalis muscles. Kaibogaku Zasshi Journal of Anatomy, 1992, vol. 67, p. 652-654. PMid:1462759

SHINOHARA, H. A warning against revival of the classic tenets of gross anatomy related to nerve-muscle specificity. Journal of Anatomy, 1996, vol. 188, Pt 1, p. 247-248. PMid:8655411 PMCid:PMC1167652 